\title{
Factors associated with disability and quality of life among the oldest-old living in community in Poland - a cross-sectional study
}

\author{
Agnieszka Beata Ćwirlej-Sozańska, ${ }^{1, A-F \oplus}$, Agnieszka Wiśniowska-Szurlej ${ }^{1, A, C-F \oplus}$, \\ Anna Wilmowska-Pietruszyńska ${ }^{2, A, E-F \oplus}$, Bernard Sozański ${ }^{1, B-C, F} \oplus$ \\ ${ }^{1}$ Institute of Health Sciences, Medical College of Rzeszow University, Rzeszow, Poland \\ ${ }^{2}$ Faculty of Medicine, Lazarski University, Warsaw, Poland \\ A - Research concept and design, B - Collection and/or assembly of data, C - Data analysis and interpretation, \\ $D$ - Writing the article, $E$ - Critical revision of the article, F - Final approval of article
}

\begin{abstract}
Ćwirlej-Sozańska AB, Wiśniowska-Szurlej A, Wilmowska-Pietruszyńska A, Sozański B. Factors associated with disability and quality of life among the oldest-old living in community in Poland - a cross-sectional study. Ann Agric Environ Med. 2020 ; $27(4)$ : 621-629. doi: $10.26444 /$ aaem/115020
\end{abstract}

\begin{abstract}
Introduction. In Poland, the number of the oldest-old people is increasing. The prevalence of health problems increases with age, which expands the cost of medical and social care. Therefore, there is a need to assess factors affecting the level of disability and quality of life in order to modify them.

Materials and method. The study was carried out in a group of 498 people aged 80 and over who live in community in south-eastern Poland. The researchers collected socio-demographic and health data, the WHODAS 2.0 questionnaire was used to assess disability and functioning. Quality of life was studied using the WHOQOL-BREF questionnaire.

Results. The general average level of disability was 37.41, with women having a higher level of general disability than men (38.94 vs. 33.94). The highest levels of disability occurred in areas such as mobility, life activity and participation. Statistically, a significantly higher level of disability develops in women who are older, with lower education, social involvement, not able to get help from other people and having more chronic diseases. In men, disability increased with age and greater number of chronic illnesses. The general quality of life of the study group was average (62.53) and comparable for both genders. The lowest quality of life was found in the domain of physical health. A significantly lower quality of life appeared in lonely people, with more chronic diseases, lower education, physical and social inactivity, as well as a lack of help from other people and non-adjustment to the environment.

Conclusion. Factors affecting the disability and quality of life of the oldest-old people should be considered in developing senior health policy in Poland.
\end{abstract}

Key words

aged, quality of life, disability evaluation

\section{INTRODUCTION}

Aging is a global phenomenon [1]. It is one of the main health challenges in most countries worldwoide, including Poland. In 2014, the number of people aged 80 and over was 774 thousand which accounted for $2 \%$ of the total population, while in 2017 it already amounted to over 1.6 million (4.3\% of the entire Polish population) [2]. Worldwide, the number of 'oldest-old' persons is growing faster than the total number of older people. Prognoses indicate that from 2017-2050 their number will have more than tripled, from 137 to 425 million [3]. The prevalence of health problems increases with age [4] and leads to a rise in the costs of medical, social and long-term care [5]. Therefore, health trends and the analysis of factors affecting the health, functioning and disability, as well as quality of life of people in the oldest age group, are particularly important when planning tasks for health care and social services and estimating the costs of this support.

Health care should concentrate on maintaining the ability to perform everyday activities and a higher level of QoL [6].

Address for correspondence: Agnieszka Ćwirlej-Sozańska, University of Rzeszow, Rzeszow, Poland

E-mail: sozanska@ur.edu.pl

Received: 03.09.2019; accepted: 22.11.2019; first published: 14.01.2020
The oldest-old are characterized by a high rate of occurrence of chronic diseases and physical disability, which influence their QoL [7]. In the elderly, the risk and incidence of cognitive impairment also increases [8]. Changes occurring in the health of the population proceed in the following way: risk factors - diseases - loss of function - disability and decline in QoL - death [9]. Disability is not only a health problem, it is a complex phenomenon showing the interaction between many factors related to a human being, as well as independent factors of the living environment and represents a close relationship with the QoL [10].

The above issues are particularly important due to the fact that data analysis from the World Health Surveys has shown that in countries such as the USA, UK, the Netherlands, Sweden and Switzerland an increase in functional limitations mainly occurs in people over 70 [11]. Older age also reduces the likelihood of recovery from disability [12]. A prospective cohort study of the elderly population in Rotterdam showed that over 6 years $18 \%$ of the population recovered from mild disability, whereas over $30 \%$ of the described group became seriously disabled and another 30\% died [13]. Lower QoL and higher level of disability was indicated in people with chronic diseases such as diabetes, arthritis and hypertension [14-16]. Stroke and psychological problems increased the risk 
of disability by about 18 times [17]. Furthermore, according to the Global Burden of Disease Report, the highest level of disability occurred in people with eye disease, hearing loss, heart disease and musculoskeletal diseases [18].

There is a small number of studies with regard to factors affecting the incidence of disability among people aged 80 and over. Data coming from highly developed countries indicates differences in the incidence of disability between men and women $[11,19]$. They are determined not only by biological determinants, but they are also dependent on modifiable psychosocial factors and lifestyle [20]. According to data from the Central Statistical Office in Poland, the incidence of chronic diseases increases with the ageing of the population [2].

\section{OBJECTIVES}

The aim of the study is to assess the level of disability and QoL and selected factors affecting them in a randomly selected population of men and women aged 80 and over living in south-eastern Poland. The following research hypothesis was formulated: older women are characterized by a higher level of disability than men and a comparable assessment of QoL. The most important factors increasing the level of disability and lowering QoL in both genders are older age, loneliness, lower education, a higher number of chronic diseases, low level of physical and social activity, higher pain intensity and the occurrence of environmental barriers.

\section{MATERIALS AND METHOD}

Study design. This is a cross-sectional study conducted on a representative population of the 'oldest-old' people living in south-eastern Poland.

Setting and procedures. The study was carried out using the Random Route method among people aged 80 and over living in the Podkarpackie Voivodeship region of southeastern Poland [21]. The researched persons were selected by multi-stage cluster sampling. The first clusters were selected according to the region of residence and size of town. Individual clusters and successively individual households were then randomly selected. The Podkarpackie Voivodeship region was divided into 4 sub-regions [22], with large, medium and small towns and villages drawn in each area. In each of the randomly selected towns and villages, the starting address was drawn. The interviewer began the survey from the drawn address - the starting place. The next address was drawn according to the rule of moving to the right from the first address. The next address was an address 3 numbers away, until the estimated number of interviews was obtained. The draw was performed using the SPSS programme.

Participants. The study was carried out in a group of 498 people aged 80 and over livinga in community in SubCarpathian region of south-eastern Poland. Inclusion parameters for participation in the study group were: age 80 and over, normal cognitive status Abbreviated Mental Test Score (AMTS) > 6 points), and informed consent for participation in the study. Exclusion criteria were: age below 80 , cognitive impairment (AMTS $\leq 6$ points), lack of informed consent to participate in the study, and being under institutional care.

The Podkarpackie Voivodeship region is inhabited by 89.4 thousand people aged 80 and over [23]. Calculation of the sample size was based on the following assumptions: 95\% (0.95) confidence level, fraction size meeting the inclusion criteria equals 0.5 , maximal estimation error of $5 \%$. It was assumed that the total planned number of surveyed people should be $n=500$. After checking the completeness of the collected data, 498 people were included in the analysis.

Variables. The study was conducted using a direct interview carried out with the Pen and Paper Interview method from March 2018 to September 2018, carried out by properly prepared and trained interviewers in the place of residence of the respondents.

Collected information concerning age, gender, height and body mass (providing BMI calculations), place of residence, education, marital status, physical activity causing panting, sweating, slight fatigue (e.g. household chores, gardening, brisk walking, sport) at least 30 minutes a day, for a total of at least 150 minutes per week. Physical exercises performed to strengthen muscles and improve physical performance and endurance, social activity, possibility to use the assistance of other persons, and adaptation of living environment to the needs of everyday functioning. Older people were asked about diseases diagnosed by a physician and compliant with ICD-10.

In order to assess the level of disability, the full version of the WHODAS 2.0 (36-point questionnaire) was used. Considering its unique feature that distinguish WHODAS 2.0 from other instruments for measuring disability, it is worth mentioning its direct relationship with the International Classification of Functioning, Disability and Health (ICF). By using this tool in the study, it was possible to assess general disability and disability in 6 areas: Cognition (D1), Mobility (D2), Self-care (D3), Getting along (D4), Life activities household (D5.1), Participation (D6). As for Life activities work / school (D5.2), were not analysed in this study owing to the age of the participants, i.e. people aged 80 and over. Respondents answered each question using a scale of 1-5, where $1=$ no difficulty, and $5=$ complete difficulty in the field of the afore-mentioned areas. The obtained results were converted on a scale from $0-100$ [24]. The results regarding the level of disability for the whole community can be displayed on a qualitative scale according to ICF, where the range from $0-4 \%$ (no disability), $5-24 \%$ (mild disability), $25-49 \%$ (moderate disability), 50 - 95\% (severe disability), while $96-100 \%$ (extreme disability) [25]. The questionnaire had previously been qualified in groups of seniors in Poland, achieving very high psychometric scores [26].

The quality of life was assessed using the WHOQOL-BREF questionnaire, a general instrument of QOL and comprises 26 questions, 2 of which measure the general health. The WHOQOL-BREF examines the QoL in 4 domains: Physical, Psychological, Social relations and Environmental. Respondents answered each question using a scale of $1-5$. The obtained results were converted on a scale from $0-100$, where $0=$ the worst QoL and $100=$ the best QoL [27].

Ethics approval. The study was approved by the Bioethical Commission of the University of Rzeszow (Resolution 
No. 4/3/2017). All participants were familiarized with the purpose and principles of the study and informed about the possibility of withdrawing from the study at any stage of the interview. Before starting the interview, the subjects signed their informed consent to participate in the study.

Statistical methods. The collected data were analysed using TIBCO Software Inc. (2017) Statistica (data analysis software system), version 13. For the initial analysis of the data, descriptive statistic measures were used. The normality of distributed variables was examined by the Shapiro-Wilk test. In order to compare the occurrence of differences in the shaping of individual variables among men and women, the following tests were used: Mann-Whitney U test, chi-square test of independence and t-test for 2 components of the structure. In order to assess the impact of chronic diseases on disability and QoL in the study groups, the following tests were used: the Mann-Whitney U test, Student's t-test for independent samples and t-test with independent variance estimation (Welch). The models of linear regression were used to assess the combined effect of factors on the level of disability and the QoL, both in the whole population and separately among men and women. The level of statistical significance was set at $\mathrm{p}<0.05$.

\section{RESULTS}

Characteristics of participants. The study involved 498 people aged 80 and over, 152 men and 346 women. The average age of the studied group was 82.66 years $(\mathrm{SD}=$ 3.44). The researched men did not differ significantly from the women in terms of place of residence, education, BMI, physical activity, and adjusting the place of residence to everyday functioning. Men more often declared being married or living with a partner, and women the membership of social organizations. They also claimed more often the possibility of using other people's help in performing their daily activities.

The prevalence of chronic diseases was very high (an average of 5.71 diseases per one person). The prevalence rate varied regarding women and men: for women, the average number of chronic diseases was higher (6.03) and significantly more often suffered from hypertension, osteoporosis, osteoarthritis of the joints and spine, spinal pain syndrome, rheumatic disease, urinary incontinence, migraine than men. In men, cancer and depression were found significantly more often than in women. The general average level of disability in the study population was $37.41(\mathrm{SD}=17.14)$, with women having a higher level of general disability than men. Severe disability was found in the domains mobility $(52.07$; $\mathrm{SD}=$ 29.44) and life activities - home duties (51.99; SD = 31.92). Women were characterized by a significantly higher level of general disability than men (38.94 vs. 33.94). A significantly higher level of disability in women was found in terms of mobility, life activity and participation in social life. The general level of QoL was at an average level $(62.53$; SD = 13.61) and was not differentiated between the genders. In women, there was a relevantly lower QoL in the domain of social relationship.

Socio-demographic data, the level of disability and QoL, as well as the prevalence rate of chronic diseases are presented in Table 1.

Table 1. Characteristics of the study sample

\begin{tabular}{|c|c|c|c|c|}
\hline & Total & Male & Female & $\mathrm{p}$-value \\
\hline & & $\begin{array}{c}\mathrm{n}(\%) \\
\text { mean (SD) }\end{array}$ & & \\
\hline Age & $82.66(3.44)$ & $82.14(2.88)$ & $82.89(3.64)$ & $0.047^{\mathrm{a}}$ \\
\hline \multicolumn{5}{|l|}{ Place of residence } \\
\hline City & $139(27.91)$ & $45(29.61)$ & $94(27.17)$ & \multirow{2}{*}{$0.577^{\mathrm{b}}$} \\
\hline Countryside & 359 (72.09) & 107 (70.39) & $252(72.38)$ & \\
\hline Body Mass Index & $26.91(4.66)$ & $26.62(4.22)$ & $27.04(4.84)$ & $0.454^{\mathrm{a}}$ \\
\hline \multicolumn{5}{|l|}{ Education } \\
\hline At most vocational & $368(73.90)$ & $108(71.05)$ & $260(75.14)$ & \multirow{2}{*}{$0.338^{\mathrm{b}}$} \\
\hline At least secondary & $130(26.10)$ & $44(28.95)$ & $86(24.86)$ & \\
\hline \multicolumn{5}{|l|}{ Marital status } \\
\hline Married or living with a partner & $193(38.76)$ & $113(74.34)$ & $80(23.12)$ & \multirow{2}{*}{$<0.001^{b}$} \\
\hline Single or widowed & $305(61.24)$ & $39(25.66)$ & $266(76.88)$ & \\
\hline \multicolumn{5}{|c|}{ Physical activity performed daily, minimum 150 minutes per week } \\
\hline No & $390(78.31)$ & $122(80.26)$ & $268(77.46)$ & \multirow{2}{*}{$0.484^{\mathrm{b}}$} \\
\hline Yes & $108(21.69)$ & $30(19.74)$ & $78(22.54)$ & \\
\hline \multicolumn{5}{|c|}{ Physical exercises performed to strengthen muscles and improve physical performance } \\
\hline No & $389(78.11)$ & $116(76.32)$ & $273(78.90)$ & \multirow{2}{*}{0.520} \\
\hline Minimum once a week & $109(21.89)$ & $36(23.68)$ & $73(21.10)$ & \\
\hline \multicolumn{5}{|c|}{ Membership of at least one organization/group/association } \\
\hline No & $343(68.87)$ & $115(75.66)$ & $228(65.90)$ & \multirow{2}{*}{$0.030^{\mathrm{b}}$} \\
\hline Yes & $155(31.13)$ & $37(24.34)$ & $118(34.10)$ & \\
\hline
\end{tabular}


Table 1. Characteristics of the study sample (Continuation)

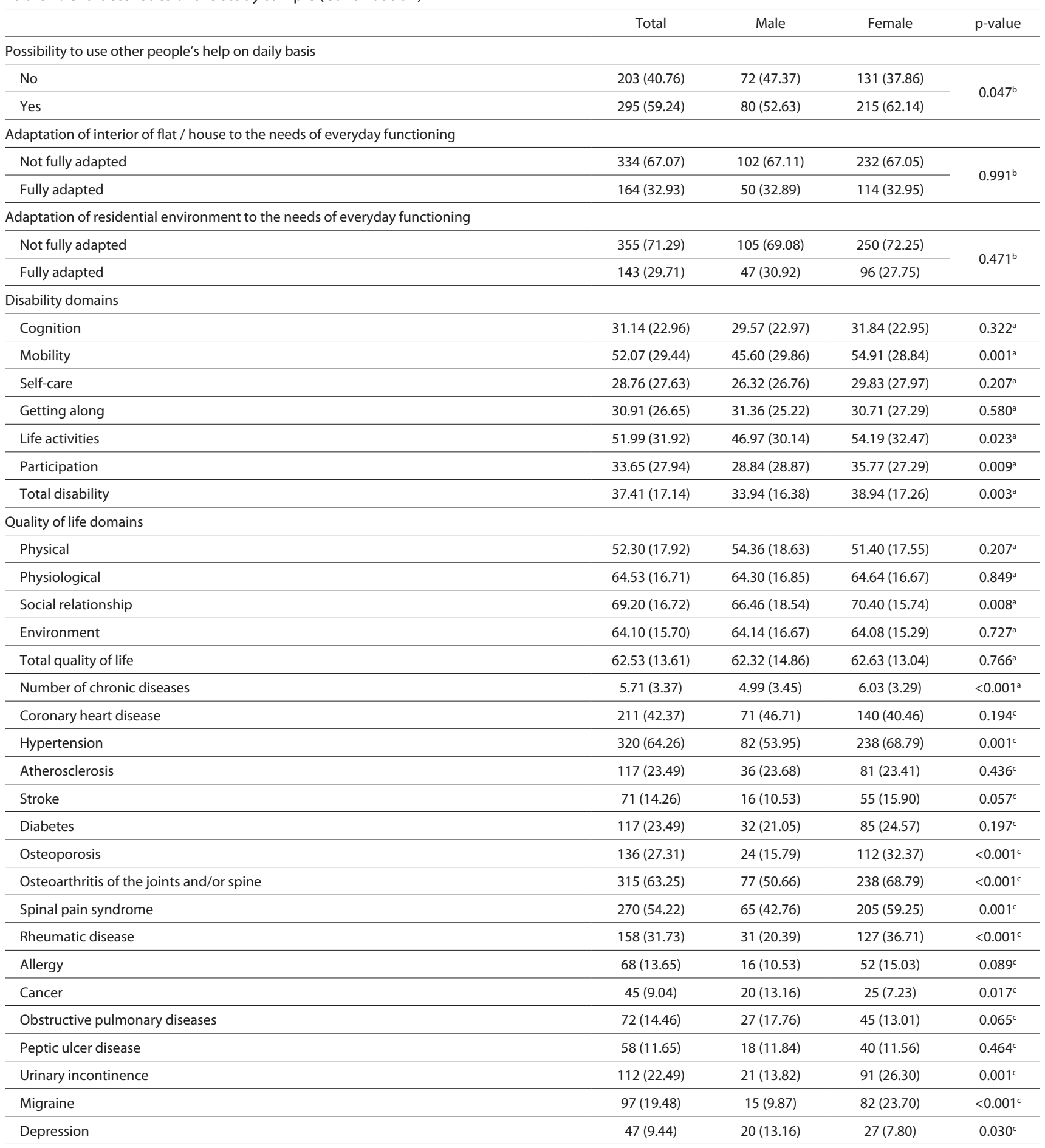

${ }^{a}$ Mann-Whitney U test

${ }^{b}$ chi-square test

ct-test for 2 components of the structure

Impact of chronic conditions on disability and QoL. The highest average general level of disability was found in people with depression (45.37). Among people with coronary heart disease, hypertension and depression, a remarkably higher level of disability occurred in women. In the case of other chronic diseases (Tab. 2), no significant distinctions in the level of disability were found between the genders. The lowest average overall QoL was found in people with depression (54.43). Moreover, there were significant differences in the QoL in women and men with osteoporosis and allergies, with significantly lower QoL in men. In the case of other chronic diseases (Tab. 2), no significant differences in the QoL were confirmed between the genders.

Impact of different factors on disability. Considering the entire surveyed population, the results obtained in the linear regression model showed that higher age, lower education, loneliness, low physical activity, lower social activity, lack of possibility to use other people's help in everyday functioning, non-adaptation of external environment to the functional 
Table 2. Influence of chronic diseases on disability and quality of life in the study groups

\begin{tabular}{|c|c|c|c|c|c|c|c|c|}
\hline & Disability & Disability Male & Disability Female & \multirow{2}{*}{$\mathrm{p}$-value } & QoL & QoL Male & QoL Female & \multirow{2}{*}{$\mathrm{p}$-value } \\
\hline & \multicolumn{3}{|c|}{ Mean $(95 \% \mathrm{Cl})$} & & \multicolumn{3}{|c|}{ Mean $(95 \% \mathrm{Cl})$} & \\
\hline $\begin{array}{l}\text { Coronary heart } \\
\text { disease }\end{array}$ & $\begin{array}{c}39.74 \\
(37.41 ; 42.08)\end{array}$ & $\begin{array}{c}34.72 \\
(31.02 ; 38.42)\end{array}$ & $\begin{array}{c}42.29 \\
(39.38 ; 45.21)\end{array}$ & $0.002^{\mathrm{d}}$ & $\begin{array}{c}61.35 \\
(59.50 ; 63.21)\end{array}$ & $\begin{array}{c}62.77 \\
(59.58 ; 65.97)\end{array}$ & $\begin{array}{c}60.63 \\
(58.33 ; 62.93)\end{array}$ & $0.254^{a}$ \\
\hline $\begin{array}{l}\text { Osteoarthritis of the } \\
\text { joints and/or spine }\end{array}$ & $\begin{array}{c}38.14 \\
(36.28 ; 40.01)\end{array}$ & $\begin{array}{c}36.01 \\
(32.38 ; 39.64)\end{array}$ & $\begin{array}{c}38.83 \\
(36.65 ; 41.01)\end{array}$ & $0.201^{\mathrm{d}}$ & $\begin{array}{c}61.86 \\
(60.40 ; 63.32)\end{array}$ & $\begin{array}{c}59.84 \\
(56.66 ; 63.03)\end{array}$ & $\begin{array}{c}62.51 \\
(60.88 ; 64.15)\end{array}$ & $0.122^{d}$ \\
\hline $\begin{array}{l}\text { Spinal pain } \\
\text { syndrome }\end{array}$ & $\begin{array}{c}38.07 \\
(36.05 ; 40.09)\end{array}$ & $\begin{array}{c}35.15 \\
(31.06 ; 39.24) \\
\end{array}$ & $\begin{array}{c}39.00 \\
(36.67 ; 41.32) \\
\end{array}$ & $0.109^{d}$ & $\begin{array}{c}61.28 \\
(59.72 ; 62.84) \\
\end{array}$ & $\begin{array}{c}60.68 \\
(56.97 ; 64.40) \\
\end{array}$ & $\begin{array}{c}61.47 \\
(59.77 ; 63.18) \\
\end{array}$ & $0.671^{d}$ \\
\hline $\begin{array}{l}\text { Obstructive } \\
\text { pulmonary diseases }\end{array}$ & $\begin{array}{c}38.21 \\
(24.11 ; 42.31)\end{array}$ & $\begin{array}{c}37.76 \\
(31.09 ; 44.43)\end{array}$ & $\begin{array}{c}38.48 \\
(33.08 ; 43.87)\end{array}$ & $0.867^{d}$ & $\begin{array}{c}60.99 \\
(58.01 ; 63.96)\end{array}$ & $\begin{array}{c}57.90 \\
(53.15 ; 62.65)\end{array}$ & $\begin{array}{c}62.84 \\
(59.00 ; 66.69)\end{array}$ & $0.109^{d}$ \\
\hline $\begin{array}{l}\text { Urinary } \\
\text { incontinence }\end{array}$ & $\begin{array}{c}42.41 \\
(39.09 ; 45.73)\end{array}$ & $\begin{array}{c}40.84 \\
(34.06 ; 47.62) \\
\end{array}$ & $\begin{array}{c}42.77 \\
(38.95 ; 46.60)\end{array}$ & $0.654^{d}$ & $\begin{array}{c}58.50 \\
(56.15 ; 60.85) \\
\end{array}$ & $\begin{array}{c}59.46 \\
(53.48 ; 65.45) \\
\end{array}$ & $\begin{array}{c}58.28 \\
(55.68 ; 60.87) \\
\end{array}$ & $0.524^{a}$ \\
\hline Hypertension & $\begin{array}{c}37.98 \\
(36.14 ; 39.82) \\
\end{array}$ & $\begin{array}{c}34.20 \\
(30.63 ; 37.77)\end{array}$ & $\begin{array}{c}39.29 \\
(37.15 ; 41.42)\end{array}$ & $0.026^{a}$ & $\begin{array}{c}63.09 \\
(61.61 ; 64.56)\end{array}$ & $\begin{array}{c}63.38 \\
(60.06 ; 66.70) \\
\end{array}$ & $\begin{array}{c}62.98 \\
(61.35 ; 64.62) \\
\end{array}$ & $0.755^{a}$ \\
\hline Diabetes & $\begin{array}{c}38.98 \\
(35.92 ; 42.04)\end{array}$ & $\begin{array}{c}38.42 \\
(33.19 ; 43.65)\end{array}$ & $\begin{array}{c}39.19 \\
(35.41 ; 42.98)\end{array}$ & $0.824^{d}$ & $\begin{array}{c}60.27 \\
(57.73 ; 62.82)\end{array}$ & $\begin{array}{c}57.22 \\
(52.06 ; 62.38) \\
\end{array}$ & $\begin{array}{c}61.42 \\
(58.48 ; 64.36)\end{array}$ & $0.369^{a}$ \\
\hline Osteoporosis & $\begin{array}{c}37.05 \\
(34.37 ; 39.73)\end{array}$ & $\begin{array}{c}36.32 \\
(29.99 ; 42.65)\end{array}$ & $\begin{array}{c}37.21 \\
(34.21 ; 40.21)\end{array}$ & $0.804^{d}$ & $\begin{array}{c}59.47 \\
(57.55 ; 61.39)\end{array}$ & $\begin{array}{c}53.94 \\
(49.35 ; 58.53)\end{array}$ & $\begin{array}{c}60.66 \\
(58.58 ; 62.74)\end{array}$ & $0.008^{d}$ \\
\hline Rheumatic disease & $\begin{array}{c}39.50 \\
(36.95 ; 42.04)\end{array}$ & $\begin{array}{c}36.47 \\
(30.73 ; 42.20) \\
\end{array}$ & $\begin{array}{c}40.23 \\
(37.36 ; 43.10)\end{array}$ & $0.431^{\mathrm{a}}$ & $\begin{array}{c}62.44 \\
(60.51 ; 64.37)\end{array}$ & $\begin{array}{c}60.83 \\
(56.16 ; 65.50) \\
\end{array}$ & $\begin{array}{c}62.83 \\
(60.69 ; 64.97)\end{array}$ & $0.419^{d}$ \\
\hline Allergy & $\begin{array}{c}36.11 \\
(32.22 ; 40.00)\end{array}$ & $\begin{array}{c}35.67 \\
(28.02 ; 43.32) \\
\end{array}$ & $\begin{array}{c}36.25 \\
(31.60 ; 40.89) \\
\end{array}$ & $0.901^{d}$ & $\begin{array}{c}64.74 \\
(61.63 ; 67.84) \\
\end{array}$ & $\begin{array}{c}59.13 \\
(51.56 ; 66.69) \\
\end{array}$ & $\begin{array}{c}66.46 \\
(63.12 ; 69.81) \\
\end{array}$ & $0.045^{d}$ \\
\hline Cancer & $\begin{array}{c}35.34 \\
(30.59 ; 40.09)\end{array}$ & $\begin{array}{c}30.82 \\
(23.17 ; 38.46) \\
\end{array}$ & $\begin{array}{c}38.96 \\
(32.88 ; 45.03) \\
\end{array}$ & $0.086^{d}$ & $\begin{array}{c}59.78 \\
(55.77 ; 63.79) \\
\end{array}$ & $\begin{array}{c}56.66 \\
(50.23 ; 63.10) \\
\end{array}$ & $\begin{array}{c}62.27 \\
(57.01 ; 67.53) \\
\end{array}$ & $0.164^{d}$ \\
\hline Peptic ulcer disease & $\begin{array}{c}36.81 \\
(32.32 ; 41.29)\end{array}$ & $\begin{array}{c}32.19 \\
(22.71 ; 41.66)\end{array}$ & $\begin{array}{c}38.89 \\
(33.81 ; 43.97) \\
\end{array}$ & $0.168^{d}$ & $\begin{array}{c}58.29 \\
(54.76 ; 61.83)\end{array}$ & $\begin{array}{c}59.90 \\
(51.48 ; 68.32) \\
\end{array}$ & $\begin{array}{c}57.57 \\
(53.82 ; 61.31) \\
\end{array}$ & $0.545^{d}$ \\
\hline Migraine & $\begin{array}{c}42.59 \\
(39.33 ; 45.86)\end{array}$ & $\begin{array}{c}38.26 \\
(33.50 ; 43.02) \\
\end{array}$ & $\begin{array}{c}43.39 \\
(39.62 ; 47.15) \\
\end{array}$ & $0.087^{e}$ & $\begin{array}{c}59.93 \\
(57.40 ; 62.45) \\
\end{array}$ & $\begin{array}{c}57.38 \\
(48.74 ; 66.02) \\
\end{array}$ & $\begin{array}{c}60.39 \\
(57.76 ; 63.02) \\
\end{array}$ & $0.559^{\mathrm{a}}$ \\
\hline
\end{tabular}

a Mann-Whitney U test

dStudent's t test for independent samples

et-test with independent variance estimation (Welch)

QoL - quality of life

Table 3. Impact of factors related to the level of disability

\begin{tabular}{|c|c|c|c|c|c|c|c|c|c|}
\hline & \multicolumn{2}{|c|}{ Disability } & \multirow{2}{*}{$\mathrm{p}$-value } & \multicolumn{2}{|c|}{ Disability Male } & \multirow{2}{*}{$\mathrm{p}$-value } & \multicolumn{2}{|c|}{ Disability Female } & \multirow{2}{*}{$\mathrm{p}$-value } \\
\hline & B & $(95 \% \mathrm{Cl})$ & & B & $(95 \% \mathrm{Cl})$ & & B & $(95 \% \mathrm{Cl})$ & \\
\hline Gender (reference female) & -1.89 & $(-5.23 ; 1.44)$ & 0.265 & & & & & & \\
\hline Age & 1.20 & $(0.81 ; 1.60)$ & $<0.001$ & 1.00 & $(0.11 ; 1.88)$ & 0.028 & 1.22 & $(0.75 ; 1.68)$ & $<0.001$ \\
\hline Place of residence (reference city) & 0.82 & $(-2.41 ; 4.05)$ & 0.618 & -0.87 & $(-6.43 ; 4.69)$ & 0.757 & 1.82 & $(-2.19 ; 5.83)$ & 0.373 \\
\hline Education (reference at least secondary) & 7.23 & $(3.94 ; 10.52)$ & $<0.001$ & 3.60 & $(-2.03 ; 9.23)$ & 0.208 & 8.81 & $(4.69 ; 12.92)$ & $<0.001$ \\
\hline $\begin{array}{l}\text { Physical activity performed daily. minimum } 150 \text { minutes per week } \\
\text { (reference yes) }\end{array}$ & 3.75 & $(0.47 ; 7.04)$ & 0.025 & 4.62 & $(-1.56 ; 10.79)$ & 0.142 & 3.19 & $(-0.81 ; 7.19)$ & 0.118 \\
\hline $\begin{array}{l}\text { Physical exercises performed to strengthen muscles and improve } \\
\text { physical performance (reference yes) }\end{array}$ & 3.18 & $(-0.29 ; 6.66)$ & 0.073 & 0.68 & $(-5.43 ; 6.79)$ & 0.826 & 3.44 & $(-0.85 ; 7.73)$ & 0.116 \\
\hline $\begin{array}{l}\text { Membership of at least one organization/group/association (reference } \\
\text { yes) }\end{array}$ & 5.34 & $(2.44 ; 8.25)$ & $<0.001$ & 4.52 & $(-1.18 ; 10.22)$ & 0.119 & 5.70 & $(2.25 ; 9.15)$ & 0.001 \\
\hline $\begin{array}{l}\text { Adaptation of interior of flat / house to the needs of everyday } \\
\text { functioning (reference fully adapted) }\end{array}$ & -0.57 & $(-4.99 ; 3.84)$ & 0.798 & 8.85 & $(-1.38 ; 19.09)$ & 0.090 & -2.64 & $(-7.62 ; 2.33)$ & 0.297 \\
\hline $\begin{array}{l}\text { Adaptation of residential environment to the needs of everyday } \\
\text { functioning (reference fully adapted) }\end{array}$ & 5.28 & $(0.69 ; 9.87)$ & 0.024 & 1.40 & $(-8.92 ; 11.72)$ & 0.789 & 5.04 & $(-0.19 ; 10.28)$ & 0.059 \\
\hline Number of diseases & 0.67 & $(0.27 ; 1.07)$ & 0.001 & 0.96 & $(0.27 ; 1.65)$ & 0.007 & 0.52 & $(0.02 ; 1.01)$ & 0.040 \\
\hline
\end{tabular}

$\mathrm{B}$ - regression coefficient; $\mathrm{Cl}$ - confidence interval; $\mathrm{QoL}$ - quality of life 
Table 4. Impact of factors related to the level of quality of life

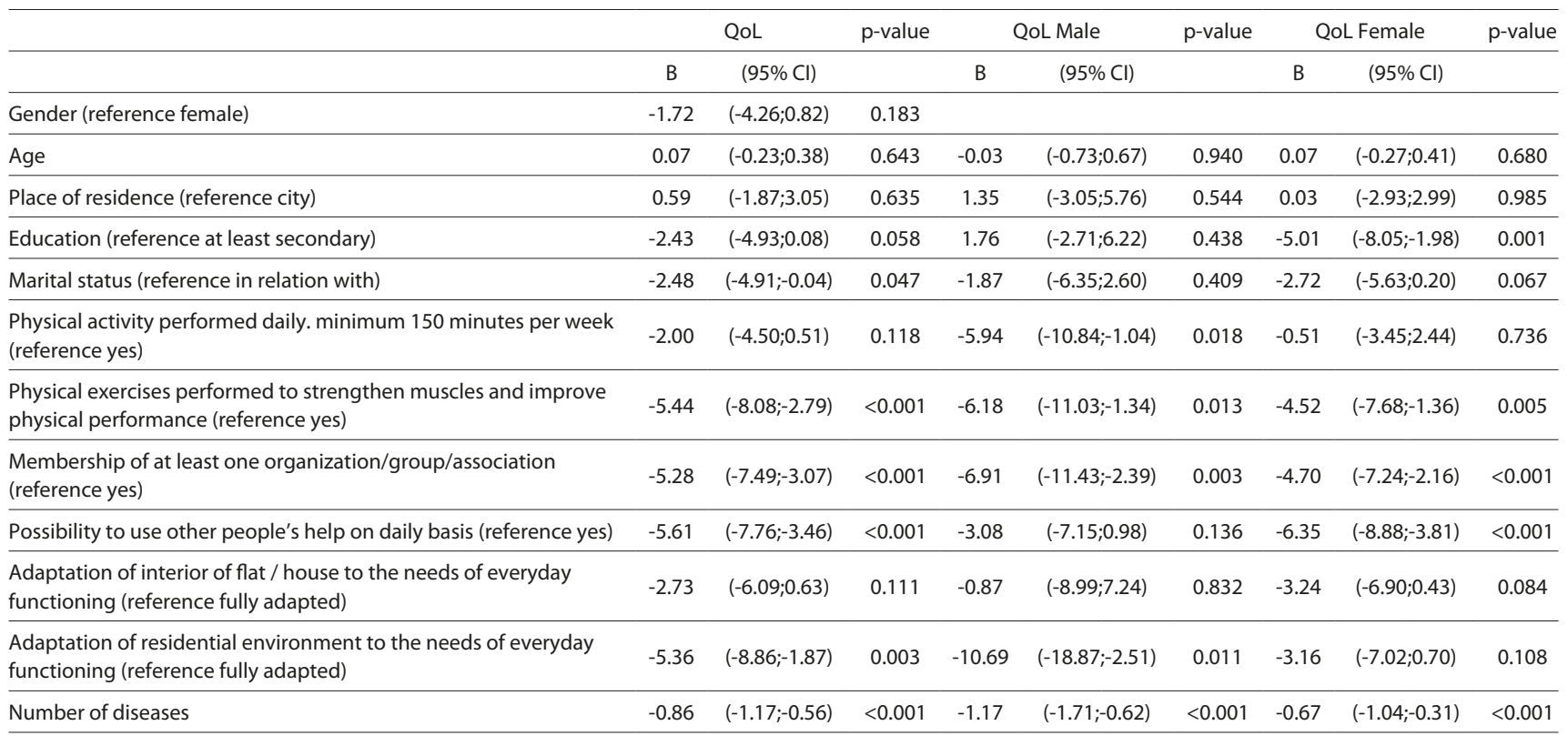

B - regression coefficient; $\mathrm{Cl}$ - confidence interval; QoL - quality of life

needs, and a higher number of chronic diseases increasing the disability level, strongly influenced people over 80 living in south-eastern Poland.

General trends presented in the research largely determined the level of disability in the group of women. As for the group of men only, important predictors of disability were primarily older age and a greater number of chronic diseases (Tab. 3).

Impact of different factors on QoL. On a global level, the model of linear regression indicated that lower QoL depends on living alone, physical and social inactivity, the inability to use the help of other people, the worse adaptation of the external environment to functional needs, and with a greater number of chronic diseases. In the group of women, additional important predictor of a worse QoL was a lower level of education (Tab. 4).

\section{DISCUSSION}

The results of the study show that the factors most associated with the occurrence of disability and lower QoL among the oldest-old inhabitants of south-eastern Poland are the following: age, low education, loneliness, low physical and social activity, lack of possibility to use other people's help, non-adaptation of the external environment to functional needs, and more chronic diseases.

The analysis carried out on the patterns of disability and QoL in older people showed that the influence of the ageing processes on QoL and disability variously depended on gender, socio-cultural and spatial contexts [28]. These findings have important implications for public authorities who are increasingly burdened with the costs resulting from the rise in life expectancy in Poland. The results of the performed research are also important for the economy. Older women often provide care services for men and children, thus enabling younger family members to work professionally. In addition, younger relatives, both men and women are excluded from active professional work in favour of the care of disabled older people [29].

This study indicates a clear tendency of increased disability with age. Earlier studies indicated that the biggest decrease in functionality declines after the age of 80 - even as much as $80 \%$ [30]. This may be due to the fact that people at an advanced age show a strong tendency to decline rapidly in function [31]. A relatively small problem, such as an influenza attack or short hospitalization, can affect the appearance of significant functional limitations, after which it is very difficult to regain health. Santosa et al. state that in the case of women the level of impairment of basic everyday activities increases with age [32]. However, there is little data available on disability and QoL using WHODAS 2.0 and WHOQOL$\mathrm{BREF}$ for the over 80 age group for both genders. The average result of the WHODAS 2.0 research conducted in China was significantly lower, compared to that observed in the current analysis (by 14.61). Lower rates of disability in the same age group were also obtained in Ghana and Mexico, while higher ones were recorded in India and Russia [33].

The differences between analyses of disability burden and lower QoL may be a reflection on the differences in the burden of chronic diseases. Obtained results in the current study confirm that disability and QoL are associated with occurring medical conditions. The results of research by Garin et al. suggest that older people with many chronic diseases require special attention due to disability burden indicators. It is important to identify groups of high risk and develop preventive and treatment strategies for elderly people with multimorbidity [34].

The presented results show the existence of a relationship between a higher level of disability as well as a reduced QoL and the occurrence of depression across the entire study group. Depression is one of the most prevalent condition causing disability among the elderly [35]. It was also indicated that impairments in physical fitness, such as the strength of upper and lower limbs, as well as the ability to perform daily activities, are both risk factors and the consequences 
of depression [36,37]. Depression, regardless of whether it is present or had occurred in the past, is a significant risk of impairment of function in the elderly, and thus establishes an important diagnostic and therapeutic goal [38].

It is worth mentioning that higher disability and lower QoL applies to women with coronary artery disease, hypertension and depression, whereas considering, they are a group with osteoporosis and allergies. Previous studies also confirmed the relationship of disability with the occurrence of hypertension and coronary disease [39]; therefore, elderly people with the indicated medical conditions should attend preventive programmes to avert the occurrence of disability and reduced QoL.

Chronic diseases account for almost two-thirds of deaths worldwide [40]. The current regression analysis shows that for both men and women, the level of disability increases with the number of chronic diseases. In the years 1990-2013, there was a significant increase in the coexistence of chronic diseases with age; thus, the number of years of life with disability caused by chronic disease burden increased to 31.2\% worldwide [41]. The US Centers for Disease Control and Prevention suggest using cross-cutting strategies. First of all, the introduction of epidemiology and surveillance to observe trends and track progress. Secondly, they mention environmental approaches to endorse and foster healthy behaviours. Health system interventions are then noted to enhance the efficacy of medical services. Finally, they enumerate community resources linked to clinical services in order to ameliorate dealing with chronic diseases [42].

With reference to the current study, it is necessary to mention that lower education ids another factor related to disability is. Previous studies have also indicated that physical disability in older people may be associated with lack of education [43]. Research conducted in the last few decades have confirmed that socio-economic factors (particularly the level of education) are strong predictors of disability, morbidity and mortality [44]. According to Sulander et al., people with a higher education have a much better ability to function independently, even after considering their age, chronic diseases and symptoms of depression [45]. It is therefore apparent that it is necessary to take into account the level of education (which will increase in future generations) in further investigations of relationships between socio-economic factors and disability. What is more, it is important to support the concept of Life Long Learning among older people, also after finishing work.

On the basis of the issues mentioned above, it is apparent that the increase in the burden of chronic diseases can be attributed to demographic changes and risk factors, including, for example, lack of physical or social activity. Research has shown that physical activity and physical exercise have a positive effect on reducing disability and improving the QoL of older people. In the meta-analysis, Tak et al. stated that physical activity prevents and slows down the ageing process of the population, as well as improving the QoL, reducing the incidence of disability and increasing independence [46]. Berlau et al., in considering the group of people aged over 90 , did not confirm a relationship between physical activity and the prevalence of disability. The authors believed that the protective effect of physical exercise may work in a younger age, and fhat from the age of 90 , exercise brings minimal benefits in preventing functional disability [47].

Moreover, the current analysis has indicated that the lack of maintaining social contacts is an important predictor of a higher level of disability and reduced QoL, especially in the case of older women. Lack of social activity among the elderly may work as a factor affecting the occurrence of a reduced QoL and disability [48]. Due to the fact that social relations are very important for maintaining a good physical condition and QoL of the elderly, healthcare providers should increase activities in the field of health promotion. It is also necessary to implement preventive home visits and group interventions for the elderly [49]. Social organizations and caregivers of older people can optimize the participation of older people in social life [50].

Furthermore, as indicated in the presented study, adaptation of the external environment to functional needs has a significant impact on the level of disability and QoL of people aged 80 and over. Similar results were obtained by Lienet al. [51] who stated that people reporting the presence of barriers in the social environment were characterized by a higher frequency of restrictions in the performance of everyday activities. Environmental barriers can limit mobility and cause the inactivity of older people. Limiting the frequency of leaving home is associated with the risk of depression, reduced physical and cognitive health, and an increase in mortality risk [52]. The adaptation of private and public buildings is essential to ensure that older people can live independently and safely in their own homes and community, regardless of age and capacity limitations [53].

This study has also shown that the opportunity to use other people's help in everyday functioning has an impact on higher QoL and allows the elderly to maintain a higher level of functioning over 80 years of age. Support from family members also plays a crucial role in the everyday functioning of older people, enabling them to continue living in their own homes [54]. The opportunity to take advantage of the help of relatives is particularly important for older people who, as they get older, need to be close and relate with their families [55]. Older people who have contact and good relations with their relatives are characterized by a better emotional state and satisfaction with life [56]. An important aspect is also the support of relatives in information transferring, which enables older people to maintain contact with the changing external world [57].

Besides, it is necessary to highlight that men were characterized by a lower overall level of disability than women. According to Oksuzyan et al., men seem to be healthier than women, but they die earlier [58]. Most articles consistently confirm the occurrence of greater disability among women in comparison with men [59]. Studies have also shown that women remain disabled for longer than men, which means that disabled women have reduced mortality compared to disabled men [60]. In contrast, men have better physical strength and fewer restrictions on performing basic everyday activities [61].

Limitations of the study. The population structure covered by the survey corresponds to the general population in terms of age and education, but it contains more people living in the countryside in comparison to people living in the city, thus it does not exactly correspond to the demographic trend in Poland. Another limitation is linked with the exclusion of people with cognitive impairment and in institutional care, which resulted from the nature of the survey conducted in the form of an interview among people living in the community. 


\section{CONCLUSIONS}

For the above-mentioned indicators, the results of the study are important for several reasons. First of all, people aged 80 and over constitute an increasing group of the general population of Poland, and the data regarding disability in this group is limited [62]. In Poland, there is no efficient medical system adapted to the needs of the oldest-old patients, and the specificity of their medical conditions. The group examined is often excluded from clinical trials and preventive interventions [63]. Regarding the current study, the World Health Organization tool based on ICF to assess disability was used, and that an average moderate level of disability was found in the examined group of older people. The study indicates very important factors that should be considered from the point of view of both clinical and social actions in order to reduce the level of disability in this group. The presented results provide valuable information that is helpful for developing preventive strategies aimed at reducing disability and improving the QoL in the group of people aged 80 and over. Additionally, the results should also be used to design geriatric rehabilitation programmes.

The most important conclusions of the study are as follows:

1) There is a high level of disability among persons aged 80 and over (the average level can be defined as moderate). Particularly high levels of disability occur in areas such as mobility, life activity and participation;

2) older women have a significantly higher level of disability than men;

3) higher age, lower education, loneliness, low physical activity, low social activity, inability to use the help of other people in everyday functioning, maladaptation of the external surroundings to functional needs and a greater number of chronic diseases, have a significant impact on the increase in the level of older people's disability;

4) general level of QoL is at an average level and does not differentiate betweengenders, and men have a significantly lower QoL only in the domain of social relationship The lowest QoL for both genders was found in the domain of physical health;

5) it was found that life in a relationship, physical and social activity, the possibility of using the help of other people, adaptation of the external environment to functional needs, have a significant impact on the higher QoL of people over the age of 80 . The QoL decreases with each subsequent chronic disease, a situation that is similar in the case of both genders.

\section{Competing interests}

The authors declare that they have no conflicts of interest.

\section{REFERENCES}

1. World Health Organization. Global Health and Aging 2011. https:// www.who.int/ageing/publications/global_health.pdf (access: 2019.11.19).

2. Central Statistical Office, Warszawa 2018. Statistics Poland. Population. Size and structure and vital statistics in Poland territorial division in 2018. As of June, 30. https://stat.gov.pl/obszary-tematyczne/ ludnosc/ludnosc/ludnosc-stan-i-struktura-oraz-ruch-naturalnyw-przekroju-terytorialnym-w-2018-r-stan-w-dniu-30-vi,6,24.html (access: 2019.03.14).

3. World World Population Aging 2017. United Union, New York, 2017. https://www.un.org/en/development/desa/population/publications/ pdf/ageing/WPA2017_Report.pdf (access. 2019.11.19)
4. Jaul E, Barron J. Age-Related Diseases and Clinical and Public Health Implications for the 85 Years Old and Over Population. Front Public Heal. 2017;5:335

5. Denzin NKLYS. The Sage handbook of qualitative research. California: Sage Publ; 2011.

6. Sprangers M, de Regt EB, Andries F, van Agt HM, Bijl R V, de Boer JB, et al. Which chronic conditions are associated with better or poorer quality of life? J Clin Epidemiol. 2000; 53: 895-907.

7. Lapid MI, Rummans TA, Boeve BF, McCormick JK, Pankratz VS, Cha RH, et al. What is the quality of life in the oldest old? Int Psychogeriatrics. 2011; 23: 1003-1010.

8. Bednarek A, Mojs E, Krawczyk-Wasielewska A, Głodowska K, Samborski W, Lisiński P, et al. Correlation between depression and burden observed in informal caregivers of people suffering from dementia with time spent on caregiving and dementia severity. Eur Rev Med Pharmacol Sci. 2016; 20: 59-63.

9. Crimmins EM. Trends in the health of the elderly. Annu Rev Public Heal. 2004; 25: 79-98.

10. World Health Organization. World report on disability 2011. https:// www.who.int/disabilities/world_report/2011/report.pdf (access: 2019.04.15)

11. Chatterji S, Byles J, Cutler D, Seeman T, Verdes E. Health, functioning, and disability in older adults--present status and future implications. Lancet. 2015 Feb 7; 385(9967): 563-75.

12. Tas Ü, Verhagen AP, Bierma-Zeinstra SMA, Odding E, Koes BW. Prognostic factors of disability in older people: a systematic review. Br J Gen Pract. 2007; 57: 319-23.

13. Tas Ü, Verhagen AP, Bierma-Zeinstra SMA, Hofman A, Pols HAP, Koes BW. Course and prognostic factors of disability in community-dwelling older people with mild disability: The Rotterdam Study. Australas J Ageing. 2012; 31: 28-33.

14. Hunter DJ, Riordan EA. The impact of arthritis on pain and quality of life: An Australian survey. Int J Rheum Dis. 2014; 17: 149-155.

15. Thompson WW, Zack MM, Krahn GL, Andresen EM, Barile JP. Healthrelated quality of life among older adults with and without functional limitations. Am J Public Health. 2012; 102: 496-502.

16. Soni RK, Porter AC, Lash JP, Unruh ML. Health-Related Quality of Life in Hypertension, Chronic Kidney Disease, and Coexistent Chronic Health Conditions. Adv Chronic Kidney Dis. 2010; 17(4): e17-26.

17. Mar J, Larrañaga I, Arrospide A, Begiristain JM. impact of disability on different domains of health- related quality of life in the noninstitutionalized general population. Clin Outcomes Res. 2010; 2: 97-103

18. Murray CJL, Lopez A. A comprehensive assessment of mortality and disability from disease, injures and risk factors in 1990 and projected to 2020. Glob Burd Dis. 1996: 1-51.

19. Andrews G, Kemp A, Sunderland M, von Korff M, Ustun TB. Normative data for the 12 item WHO disability assessment schedule 2.0. PLoS One. 2009; 4(12): e8343.

20. Gjonça A, Tomassini C, Toson B, Smallwood S. Sex differences in mortality, a comparison of the United Kingdom and other developed countries. Heal Stat Q. 2005; 26: 6-16.

21. Bauer J. Biases in Random Route Surveys. J Surv Stat Method. 2016; 4(2): 263-287

22. Commission Regulation (EU) 2016/2066 of 21 November 2016 amending the annexes to Regulation (EC) No 1059/2003 of the European Parliament and of the Council on the establishment of a common classification of territorial units for statistics (NUTS).

23. Statystyczne Vademecum Samorządowca. Województwo Podkarpackie. Urząd Statystyczny w Rzeszowie 2018 https://rzeszow.stat.gov.pl/ vademecum/vademecum_podkarpackie/portret_wojewodztwa/ wojewodztwo_podkarpackie.pdf (access: 2019.05.04).

24. Üstün TB, Kostanjsek N, Chatterji S, Rehm J. Measuring Health and Disability: Manual for WHO Disability Assessment Schedule WHODAS 2.0. Geneva. WHO 2010.https://books.google.com/books? $\mathrm{hl}=\mathrm{en} \& \mathrm{lr}=\& \mathrm{id}=\mathrm{h} 9 \mathrm{fhLNiaRTgC \& pgis}=1$ (access: 2019.05.04).

25. Salomon JA, Wang H, Freeman MK, Vos T, Flaxman AD, Lopez AD, et al. Healthy life expectancy for 187 countries, 1990-2010: a systematic analysis for the Global Burden Disease Study 2010. Lancet. 2012; 380: 2144-2162.

26. Ćwirlej-Sozańska A, Wilmowska-Pietruszyńska A, Sozański B. Validation of the Polish version of the World Health Organization Disability Assessment Schedule (WHODAS 2.0) in an elderly population (60-70 years old). Int J Occup Saf Ergon. 2018; 24(3): 386-394.

27. Quality of Life Group. Development of the World Health Organization WHOQOL-BREF quality of life assessment. The WHOQOL Group. Psychol Med. 1998; 28(3): 551-558. 
28. Gomez-Olive FX, Schröders J, Aboderin I, Byass P, Chatterji S, Davies JI, et al. Variations in disability and quality of life with age and sex between eight lower income and middle-income countries: data from the INDEPTH WHO-SAGE collaboration. BMJ Glob Heal. 2017; 2: e000508.

29. Langer A, Meleis A, Knaul FM, Atun R, Aran M, Arreola-Ornelas H, et al. Women and Health: The key for sustainable development. Lancet. 2015; 386(9999): 1165-210.

30. Van Houwelingen AH, Cameron ID, Gussekloo J, Putter H, Kurrle S, De Craen AJM, et al. Disability transitions in the oldest old in the general population. The Leiden 85-plus study. Age (Omaha). 2014; 36: 483-493.

31. McCusker J, Kakuma R, Abrahamowicz M. Predictors of functional decline in hospitalized elderly patients: A systematic review.J Gerontol A Biol Sci Med Sci. 2002; 57(9): M569-77.

32. Santosa A, Schröders J, Vaezghasemi M, Ng N. Inequality in disabilityfree life expectancies among older men and women in six countries with developing economies. J Epidemiol Community Health. 2016; 70: 855-861.

33. Biritwum RB, Minicuci N, Yawson AE, Theou O, Mensah GP, Naidoo $\mathrm{N}$, et al. Prevalence of and factors associated with frailty and disability in older adults from China, Ghana, India, Mexico, Russia and South Africa. Maturitas. 2016; 91: 8-18.

34. Garin N, Olaya B, Moneta MV, Miret M, Lobo A, Ayuso-Mateos JL, et al. Impact of multimorbidity on disability and quality of life in the Spanish older population. PLoS One. 2014; 9(11): e111498.

35. Verhaak PFM, Dekker JH, De Waal MWM, Van Marwijk HWJ, Comijs HC. Depression, disability and somatic diseases among elderly. J Affect Disord. 2014; 167: 187-91.

36. Bruce ML. Depression and disability in late life: Directions for future research. Am J Geriatr Psychiatry. 2001; 9: 102-12.

37. Lenze EJ, Schulz R, Martire LM, Zdaniuk B, Glass T, Kop WJ, et al. The course of functional decline in older people with persistently elevated depressive symptoms: Longitudinal findings from the cardiovascular health study. J Am Geriatr Soc. 2005; 53: 569-575.

38. Pocklington C. Depression in older adults. Br J Med Pract. 2017; 10(1): a1007.

39. Iritani O, Koizumi Y, Hamazaki Y, Yano H, Morita T, Himeno T, et al. Association between blood pressure and disability-free survival among community-dwelling elderly patients receiving antihypertensive treatment. Hypertens Res. 2014; 37: 772-778.

40. Alwan A. WHO Global status report on non-communicable diseases 2010. WHO 2010;176. http://whqlibdoc.who.int/ publications/2011/9789240686458_eng.pdf (access: 2019.05.10).

41. Vos T, Allen C, Arora M, Barber RM, Bhutta ZA, Brown A, et al. Global, regional, and national incidence, prevalence, and years lived with disability for 310 diseases and injuries, 1990-2015: a systematic analysis for the Global Burden of Disease Study 2015. Lancet. 2016;388:15451602 .

42. Bauer UE, Briss PA, Goodman RA, Bowman BA. Prevention of chronic disease in the 21st century: Elimination of the leading preventable causes of premature death and disability in the USA. Lancet. 2014;384:45-52.

43. Khongboon P, Pongpanich S, Chapman RS. Risk Factors for Six Types of Disability among the Older People in Thailand in 2002, 2007, and 2011. J Aging Res. 2016; 6475029.

44. Ansah JP, Malhotra R, Lew N, Chiu CT, Chan A, et al. Projection of young-old and old-old with functional disability: Does accounting for the changing educational composition of the elderly population make a difference? PLoS One. 2015; 10: e0126471.
45. Sulander T, Martelin T, Sainio P, Rahkonen O, Nissinen A, Uutela A. Trends and educational disparities in functional capacity among people aged 65-84 years. Int J Epidemiol. 2006; 35: 1255-61.

46. Tak E, Kuiper R, Chorus A, Hopman-Rock M. Prevention of onset and progression of basic ADL disability by physical activity in community dwelling older adults: A meta-analysis. Ageing Res Rev. 2013; 12: 329-338.

47. Berlau DJ, Corrada MM, Peltz CB, Kawas CH. Disability in the oldestold: Incidence and risk factors in the 90+ study. Am J Geriatr Psychiatry. 2012; 20: 159-68.

48. Golden J, Conroy RM, Lawlor BA. Social support network structure in older people: Underlying dimensions and association with psychological and physical health. Psychol Heal Med. 2009; 14: 280-290.

49. Tribble DSC, Gallagher F, Bell L, Caron C, Godbout P, Leblanc J, et al. Empowerment interventions, knowledge translation and exchange: Perspectives of home care professionals, clients and caregivers. BMC Health Serv Res. 2008; 8: 177.

50. Turcotte PL, Larivière N, Desrosiers J, Voyer P, Champoux N, Carbonneau $\mathrm{H}$, et al. Participation needs of older adults having disabilities and receiving home care: Met needs mainly concern daily activities, while unmet needs mostly involve social activities. BMC Geriatr. 2015; 15: 95.

51. Lien WC, Guo NW, Chang JH, Lin YC, Kuan TS. Relationship of perceived environmental barriers and disability in communitydwelling elderly in Taiwan - A population-based study. BMC Geriatr. 2014; 14: 59.

52. Rantakokko M, Törmäkangas T, Rantanen T, Haak M, Iwarsson S. Environmental barriers, person-environment fit and mortality among community-dwelling very old people. BMC Public Health. 2013; 13: 783.

53. Ahn M. Introduction to special issue: aging in place. Hous Soc. 2017; 44: $1-3$.

54. Ris I, Schnepp W, Mahrer Imhof R. An integrative review on family caregivers' involvement in care of home-dwelling elderly. Heal Soc Care Community. 2018 Oct 11. doi: 10.1111/hsc.12663.

55. Carstensen LL, Isaacowitz DM, Charles ST. Taking time seriously: A theory of socioemotional selectivity. Am Psychol. 1999; 54: 165-81.

56. Kashaniyan F, Khodabakhshi Koolaee A. Effectiveness of Positive Psychology Group Interventions on Meaning of Life and Life Satisfaction among Older Adults. Elder Heal Journalir Elder Heal J. 2015; 1 : 68-74.

57. Pálsdóttir Á. Elderly peoples' information behaviour: Accepting support from relatives. Libri. 2012; 62: 135-44.

58. Oksuzyan A, Juel K, Vaupel JW, Christensen K. Men: Good health and high mortality. Sex differences in health and aging. Aging Clin Exp Res. 2008; 20(2): 91-102.

59. Yi Z, Yuzhi L, George LK. Gender differentials of the oldest old in China. Res Aging. 2003; 25: 65-80.

60. Oh MS, Yu KH, Roh JK, Lee BC. Gender differences in the mortality and outcome of strokepatients in Korea. Cerebrovasc Dis. 2009; 28: 427-34.

61. Frederiksen H, Hjelmborg J, Mortensen J, Mcgue M, Vaupel JW, Christensen K. Age Trajectories of Grip Strength: Cross-Sectional and Longitudinal Data Among 8,342 Danes Aged 46 to 102. Ann Epidemiol. 2006; 16: 554-62.

62. Vaupel JW. Biodemography of human ageing. Nature. 2010; 464 (7288): 536-542.

63. De Boer MJ, Ottervanger JP, Suryapranata H, Hoorntje JCA, Dambrink JHE, Gosselink ATM, et al. Old age and outcome after primary angioplasty for acute myocardial infarction. J Am Geriatr Soc. 2010; 58: $867-72$. 